\title{
REACHING PEAK EMISSIONS
}

Robert B. Jackson ${ }^{1} *$, Josep G. Canadell ${ }^{2}$, Corinne Le Quéré ${ }^{3}$, Robbie M. Andrew ${ }^{4}$, Jan Ivar Korsbakken $^{4}$, Glen P. Peters ${ }^{4}$, Nebojsa Nakicenovic ${ }^{5}$

${ }^{1}$ School of Earth, Energy, and Environmental Sciences, Woods Institute for the Environment, and Precourt Institute for Energy, Stanford University, Stanford, CA, 94305

${ }^{2}$ Global Carbon Project, CSIRO Oceans and Atmosphere, Canberra, ACT 2601, Australia ${ }^{3}$ Tyndall Centre for Climate Change Research, University of East Anglia, Norwich Research Park, Norwich NR4 7TJ, UK

${ }^{4}$ Center for International Climate and Environmental Research - Oslo, P.O. Box 1129 Blindern, 0318 Oslo, Norway ${ }^{5}$ International Institute for Applied Systems Analysis, Schlossplatz 1, 2361 Laxenburg, Austria

*email: rob.jackson@stanford.edu

Keywords: carbon dioxide; climate change; cumulative emissions; global warming, mitigation targets

Standfirst: Rapid growth in global $\mathrm{CO}_{2}$ emissions from fossil fuels and industry ceased in the past two years, despite continued economic growth. Decreased coal use in China was largely responsible, coupled with slower global growth in petroleum and faster growth in renewables.

Reining in greenhouse gas emissions has been an international priority for decades. Under the United Nations Framework Convention on Climate Change (UNFCCC) adopted in 1992, the Kyoto Protocol (1997) set legally binding targets for cutting emissions in economically developed countries, and the Copenhagen Accord (2009) highlighted the 
importance of keeping average global temperature increases below $2^{\circ} \mathrm{C}$. After more than two decades of negotiations, the member states of the UNFCCC are meeting in Paris for the $21^{\text {st }}$ Conference of the Parties (COP) to forge a new agreement and set mitigation targets post2020. Here, we look back on some successes and missed opportunities for climate mitigation since 1990, the benchmark year for the Kyoto Protocol. We also present new data for 2014 and a projection for 2015 indicating that the rapid growth in global $\mathrm{CO}_{2}$ emissions from fossil fuels and industry since 2000 slowed dramatically in the past two years (Figure 1), despite continued global economic growth. Time will tell whether this surprising interruption in emissions growth is transitory or a first step towards emissions stabilization. In either case the trend is a welcome change from the historical coupling of $\mathrm{CO}_{2}$ emissions with economic growth and should be strengthened through efforts at the Paris COP and beyond.

Many climate and emissions milestones were reached over the past year. Fourteen of the fifteen hottest years on record have occurred since 2000, with 2015 on track to be the first year to top $1^{\circ} \mathrm{C}$ average warming globally ${ }^{1}$. This year, the Earth also topped $400 \mathrm{ppm}$ in average monthly atmospheric $\mathrm{CO}_{2}$ concentration for the first time in at least 800,000 years. We have already emitted two thirds of the total carbon allocation to the atmosphere that would ensure at least a $66 \%$ chance of limiting global temperature increases to below $2{ }^{\circ} \mathrm{C}^{2,3}$.

In contrast to these negative benchmarks, global $\mathrm{CO}_{2}$ emissions are showing some encouraging trends. $\mathrm{CO}_{2}$ emissions from fossil-fuel consumption and cement production in 2014 grew by only $0.6 \%$, compared with $2.4 \%$ annual growth for the decade before (Figures 1 and 2). (See Supplementary Information and Le Quéré et al. ${ }^{4}$ for methods and additional information on the new $\mathrm{CO}_{2}$ budget from the Global Carbon Project (GCP).) The slower growth in emissions was attributed largely to a drop in coal consumption in China, with additional contributions from below-average growth in global demand for oil and natural gas and continuing growth in renewables ${ }^{5}$ (Figure 3). Based on data through June to October, our projection for global $\mathrm{CO}_{2}$ emissions in 2015 indicates a decline of $0.6 \%$ ( $-1.6 \%$ to $+0.5 \%$ range), from $\sim 35.9 \mathrm{CO}_{2}$ in 2014 to $\sim 35.7 \mathrm{Gt} \mathrm{CO}_{2}$ in 2015 (Figure 1). Unlike past periods with little or no emissions growth, global gross domestic product (GDP) grew in both years. 
As nations prepare for the approaching UNFCCC $21^{\text {st }}$ Conference of the Parties in Paris, we first examine some of the mitigation approaches that have been the most successful historically, using the framework of stabilization wedges ${ }^{6}$. We then compare the past and newest data for $\mathrm{CO}_{2}$ emissions to understand the short-term trajectory and implications for global peak emissions.

\section{Mitigation Progress and Missed Opportunities}

The concept of "stabilization wedges" offers a framework to examine progress in reducing $\mathrm{CO}_{2}$ emissions and future climate change ${ }^{6}$. A wedge was defined as an activity that would reduce total emissions by $\sim 90 \mathrm{Gt} \mathrm{CO}_{2}$ over a fifty-year period ending around 2050 , with seven or more wedges needed for full decarbonization ${ }^{6}$.

Two activities on pace to be successful wedges are increased global wind and solar capacities. To constitute a complete wedge, wind and solar individually must grow by 2,000 GW of installed global capacity within fifty years and primarily offset fossil fuel power. Installed wind capacity reached $370 \mathrm{GW}$ in 2014, including $51 \mathrm{GW}$ of newly installed capacity that year, an amount greater than the global total capacity only a decade ago ${ }^{7}$. China, the world's largest wind producer, installed $23 \mathrm{GW}$ of new wind capacity last year alone. Similarly, total installed solar photovoltaic (PV) capacity jumped from $3.7 \mathrm{GW}$ in 2004 to $178 \mathrm{GW}$ in 2014, with $40 \mathrm{GW}$ of new PV capacity installed in $2014^{8}$. Incentives for renewable power and, in places, price parity between renewables and fossil fuels guarantee their continued growth (Figure 3).

Efforts to reduce land-based emissions, particularly deforestation, and several other wedges have been at least partially successful. In the $1990 \mathrm{~s}$, the average net $\mathrm{CO}_{2}$ emissions from land-use change were $5.5 \pm 2.9 \mathrm{Gt} \mathrm{CO}_{2} / \mathrm{yr}^{9}$. Average emissions from land-use change appear to have dropped to $\sim 4.0 \mathrm{Gt} \mathrm{CO}_{2} / \mathrm{yr}$ during the $2000 \mathrm{~s}$ and to $\sim 2.9 \mathrm{Gt} \mathrm{CO}_{2} / \mathrm{yr}$ in the current decade $^{9,10}$, although the magnitude of the decrease has large uncertainties ${ }^{9,11}$. The cumulative savings from the past decade was roughly $20 \mathrm{Gt} \mathrm{CO}_{2}^{4,10}$. Conservation tillage, biomass fuels, and vehicle-fuel and building efficiency have all increased over the past decade, though not on pace to become full wedges by 2050 . 
Most other stabilization wedges have been less successful. The nuclear accident in Fukushima, Japan, the phase-out of nuclear power in countries such as Germany and Switzerland, and the continued high cost of nuclear power have stalled global nuclear capacity at around $380 \mathrm{GW}$. In fact, nuclear electricity generation fell 8\% between 2004 and 2014, from 2760 to $2537 \mathrm{TW}-\mathrm{hrs}^{5}$. Other wedges that have shown little progress to date include four wedges associated with carbon capture and storage technologies and fuel-cell vehicles powered by renewable-generated hydrogen $\left(\mathrm{H}_{2}\right)$. These and additional wedges have large potentials for reducing future global emissions of $\mathrm{CO}_{2}$ consistent with safer climate stabilization $^{12}$.

\section{Could $\mathrm{CO}_{2}$ Emissions Peak Soon?}

Our projected decline of $0.6 \%$ (range of $-1.6 \%$ to $+0.5 \%$ ) in global $\mathrm{CO}_{2}$ emissions for 2015 follows the surprisingly low growth of $+0.6 \%$ in 2014 , and contrasts with $+2.4 \% / y r$ average growth for the previous decade ${ }^{4}$ (2004-2013; Figure 1). What makes the 2014 and 2015 data so unusual is the pairing of relatively stable $\mathrm{CO}_{2}$ emissions with continued global economic expansion. In recent decades, stable or declining emissions occurred during economic downturns, including the breakup of the Soviet Union in the early 1990s, the subsequent economic collapse of Russia and other former Soviet Union countries from 1997 to 1999 , the dot-com and financial crises of the late 1990s and 2000s, and the recent Global Financial Crisis ${ }^{13}$. In contrast, global GDP grew at a stable rate of 3.3-3.4\%/yr during 2012, 2013, and 2014 and is projected to grow a further 3.1\% in $2015\left(\mathrm{IMF}^{14}\right)$. The decoupling of fossil fuel emissions and global GDP reduced the carbon intensity of the global economy by $2.7 \%$ in 2014; our projection for 2015 indicates a 3.7\% reduction, compared with an average $1.1 \%$ for the decade before (Figure 1). Two questions naturally arise from these new data: What is causing the break and does it signal the beginning of a reversal in global emissions growth?

After rising 6.7\%/ yr for the previous decade, China's emissions growth slowed to $1.2 \%$ in 2014 (Figure 2). The lower growth in China's emissions compared to the previous year was driven primarily by relatively stable coal use (measured in energy terms) ${ }^{15}$. Because 
$58 \%$ of the increase in China's primary energy consumption from 2013-2014 came from nonfossil-fuel sources (hydro, nuclear, and other renewables), compared with $24 \%$ for increased natural gas and $17 \%$ for oil ${ }^{5,15}$ (Figure 3), China's stabilization of, and even reduction in, coal use might be sustainable longer term.

Even more unexpectedly, our projection indicates a decline of $\sim 3.9 \%$ for China's emissions in 2015 (a range of $-4.6 \%$ to $-1.1 \%$ ), amounting to an absolute decrease of $0.4 \mathrm{Gt}$ $\mathrm{CO}_{2}$ (Figure 2). This projection is largely a result of a decline in coal consumption for at least the first eight months of 2015 (the latest date for which data were available; see Supplementary Information).

Considerable uncertainty is associated with estimates of China's national emissions, as highlighted by a study claiming emissions were lower than reported ${ }^{16}$. The Chinese government recently released revised energy statistics for 2000 through 2013, including an upwards revision of coal consumption of as much as $14 \%$ annually and $9.5 \%$ for the entire period, when measured by energy content ${ }^{17}$. Our growth rates for years after 2011, including our projection for China for 2015, are already based on these revised data. Absolute emissions may ultimately be revised upwards slightly, but if they are, the recent decline in emissions for 2015 is unaffected and could even drop from $-0.6 \%$ to $-0.8 \%$. Additional analysis of the revised emissions data from China will take some time (see Supplementary Information).

China's per capita GDP is only one quarter that of the United States, and thus further GDP and emissions growth is expected. Even if China's emissions do not peak until its committed date of 2030, a more modest growth rate of $1-2 \% / y r$ over the next decade would be consistent with China's INDC, and a substantial improvement over the previous decade ${ }^{17}$. Based on China's INDC, a 60 or $65 \%$ reduction in emissions intensity could result in Chinese emissions that are slightly higher than those of today $\left(9.9 \text { to } 11.3 \mathrm{Gt} \mathrm{CO}_{2} / \mathrm{yr} \text { in } 2030\right)^{18}$.

In the European Union, the region with the strongest emission declines (Figure 2), emissions decreased by $2.4 \%$ per year on average between 2005 and 2014 and by $4.1 \% / y r$ for 2012 through 2014. Although the outsourcing of emissions to emerging economies played a substantive role in the earlier reductions, emissions transfers from the EU to China and 
elsewhere have declined since $2007^{4}$. Energy efficiency and renewables policies have also played a role in the declining emissions. For example, legally binding targets for renewable energy enacted by EU Directive 2009/28/EC helped drive renewables to 15\% of total gross energy consumed there in $2013^{19}$. The EU's INDC is a 40\% reduction below 1990 emissions levels by $2030^{18}$.

Emissions in the United States and Canada have declined from 2005 through 2014 at rates of $1.4 \% / \mathrm{yr}$ and $0.6 \% / \mathrm{yr}$, respectively (although emissions in both countries increased slightly from 2012 to 2014). In contrast, Australia's $\mathrm{CO}_{2}$ emissions have been flat for the past decade $(0.1 \%$ average growth), with declining emissions of $2.1 \% / \mathrm{yr}$ from 2012 to 2014 . Through their INDCs, the United States and Australia are both intending to reduce emissions 26 to $28 \%$ by 2025 and 2030, respectively. Canada's commitment is to reduce greenhouse gas emissions 30\% below 2005 levels by 2030. For the United States, the planned emissions decline to 2020 approximates the decadal trend of $-1.5 \% / \mathrm{yr}$, with a larger decline of $2 \% / \mathrm{yr}$ on average planned between 2020 and 2025. Canada's and Australia's intended emissions reductions are considerably faster than their actual rates of decline for the past decade.

India is another vital country in the attempt to stabilize global $\mathrm{CO}_{2}$ emissions. India's emissions of $2.4 \mathrm{Gt} \mathrm{CO}_{2} / \mathrm{yr}$ today match those of China in 1990. Its challenge, however, is the need to provide 1.3 billion people with greater access to energy, including 300 million people unconnected to an electrical grid. India's INDC target for 2030 is to reduce GDP-based emissions intensity $33-35 \%$ compared to 2005 levels. This target combined with estimates of long-term GDP from the Organization of Economic Co-Operation and Development suggest that India's $\mathrm{CO}_{2}$ emissions could grow to about 4.2-4.5 $\mathrm{Gt} \mathrm{CO}_{2} / \mathrm{yr}$ by 2030 . Increasing emissions to $\sim 4.5 \mathrm{Gt} \mathrm{CO}_{2} / \mathrm{yr}$ would raise India's per capita emissions to $\sim 3.0 \mathrm{tCO}_{2} / \mathrm{yr}$ per person, still well below current values for China $\left(7.4 \mathrm{tCO}_{2} / \mathrm{yr}\right)$ and the United States $(16.5$ $\mathrm{tCO}_{2} / \mathrm{yr}$ ). For global $\mathrm{CO}_{2}$ emissions to peak quickly, part of India's new energy needs must come from low-carbon technologies. However, India had only $34 \mathrm{GW}$ of renewable capacity installed at the end of 2013, and only $3 \mathrm{GW}$ of solar power. A more robust electrical grid and a dramatic rise in renewables are greatly needed. Many other emerging economies and lower-income countries are in a similar position. 
We have shown that the high growth rates in global $\mathrm{CO}_{2}$ emissions prevalent since the early 2000 s ceased in the last two years, at least temporarily, despite robust growth in global economic activity (Figures 1 and 2). Underlying trends in some emerging and established economies suggest that structural changes in their economies and energy systems are already leading to emission reductions. However, China's emissions growth rate will strongly influence this outcome over the next decade (Figures 2 and 3).

Whether the unexpectedly low growth rates in $\mathrm{CO}_{2}$ emissions observed in 2014 and 2015 are a first sign of an approaching global peak emissions is unclear. Current INDC pledges suggest that, even if peak emissions were to occur soon, global emissions would still take years to decline. An acceleration in the transformation of energy use and production is needed to set global emissions on course to complete decarbonisation, as required for climate stabilization.

\section{Acknowledgements}

This work is a collaborative effort of the Global Carbon Project, part of the International Geosphere-Biosphere Program and Future Earth, to provide regular analyses of the main global carbon emissions and sinks (http://www.globalcarbonproject.org). The authors wish to thank the U.S. Carbon Cycle Science Program and Stanford University (RBJ), the Australian Climate Change Science Program (JGC), Research Council of Norway projects 236296 and 209701 (RMA, JIK, and GPP), and the UK Natural Environment Research Council International Opportunities Fund (NE/103002X/1) (CLQ) for their support. 


\section{References}

1. World Meteorological Organization (2015); https://www.wmo.int/media/content/januaryjune-2015-hottest-record-noaa (accessed September 1, 2015).

2. Friedlingstein, P. et al. Nature Geosci. 7, 709-715 (2014).

3. Jackson, R.B., Friedlingstein, P., Canadell, J.G., Andrew, R.M. The Bridge 45, 16-21 (2015).

4. Le Quéré, C. et al. Earth Syst. Sci. Data (2015).

5. British Petroleum, Statistical Review of World Energy 2015 (2015).

6. Pacala, S. \& Socolow, R. Science 305, 968-972 (2004).

7. Global Wind Energy Council (2015) Global Wind Report Annual Market Update 2014; http://www.gwec.net/publications/global-wind-report-2/global-wind-report-2014-annualmarket-update/. Retrieved 21 August 2015.

8. International Energy Agency (2015) Snapshot of Global PV Markets 2014; http://www.iea-pvps.org/index.php?id=32. Accessed 21 August, 2015.

9. IPCC AR5 WGIII Chapter 11 (2014)

10. Federici, S. et al. Forest Ecol. Manage. 352, 89-98 (2015).

11. Achard, F. et al. Glob. Change Biol. 20, 2540-2554 (2014).

12. Davis, S.J. \& Socolow, R.H. Environ. Res. Lett. 9, 084018 (2014).

13. Peters, G.P. et al. Nature Clim. Change 2, 2-4 (2012).

14 International Monetary Fund (2015) Adjusting to Lower Commodity Prices; http://www.imf.org/external/pubs/ft/survey/so/2015/RES100615A.htm (accessed 10 October 2015).

15. National Bureau of Statistics of China. 2015 China Statistical Yearbook. China Statistics Press, Beijing (2015). ISBN 978-7-5037-7638-0.

16. Liu, Z. et al. Nature 524, 335-338 (2015).

17. National Bureau of Statistics of China. China Energy Statistical Yearbook 2014. China Statistics Press, Beijing (2015). ISBN 978-7-5037-7499-7.

18. Peters, G.P., Andrew, R.M., Solomon, S. \& Friedlingstein, P. Environ. Res. Lett. 10, 105004 (2015). 
In press, do not cite or quote until published (7 December 4pm UK)

19. Eurostat, European Commission; http://appsso.eurostat.ec.europa.eu/nui/show.do (accessed 20 October 2015). 


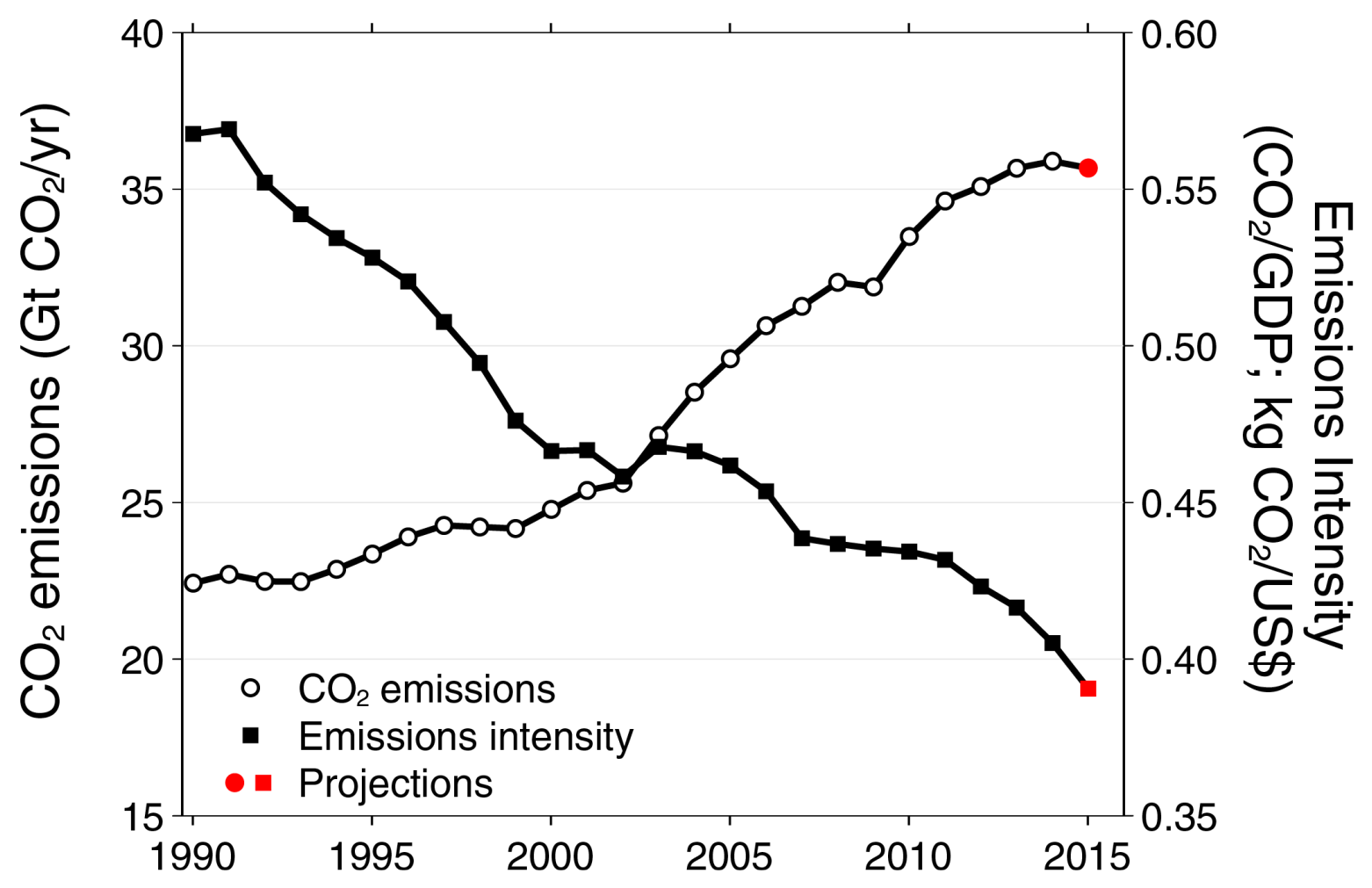

Figure 1. Global $\mathrm{CO}_{2}$ emissions $\left(\mathrm{Gt} \mathrm{CO}_{2} / \mathrm{yr}\right)$ from fossil-fuel use and industry since 1990 (circles) and emissions intensity $\mathrm{CO}_{2} / \mathrm{GDP}$ in units of $\mathrm{kg} \mathrm{CO}_{2} / \mathrm{U} . \mathrm{S}$.\$) (squares). The red symbols are projections for 2015 . 


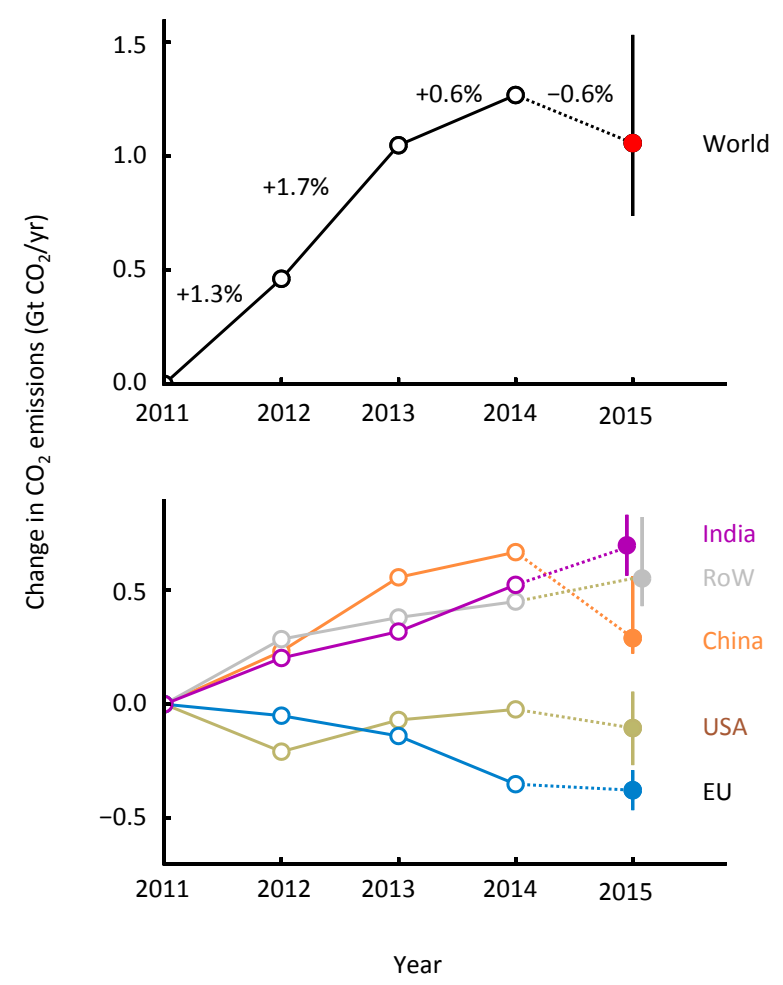

Figure 2. Change in $\mathrm{CO}_{2}$ emissions $\left(\mathrm{Gt} \mathrm{CO}_{2} / \mathrm{yr}\right)$ from fossil-fuel use and industry since 2011 .

a. Yearly change in global $\mathrm{CO}_{2}$ emissions relative to 2011. b. Yearly change in $\mathrm{CO}_{2}$ emissions for the European Union (blue), United States (green), China (orange), India (purple), and rest of the world (ROW) relative to 2011 (gray). The most recent projected change in emissions is from $\sim 35.9 \mathrm{CO}_{2}(9.8 \mathrm{Gt} \mathrm{C})$ in 2014 to $~ 35.7 \mathrm{Gt} \mathrm{CO}_{2}(9.7 \mathrm{Gt} \mathrm{C})$ in 2015. The solid symbols for 2015 denote projections. 

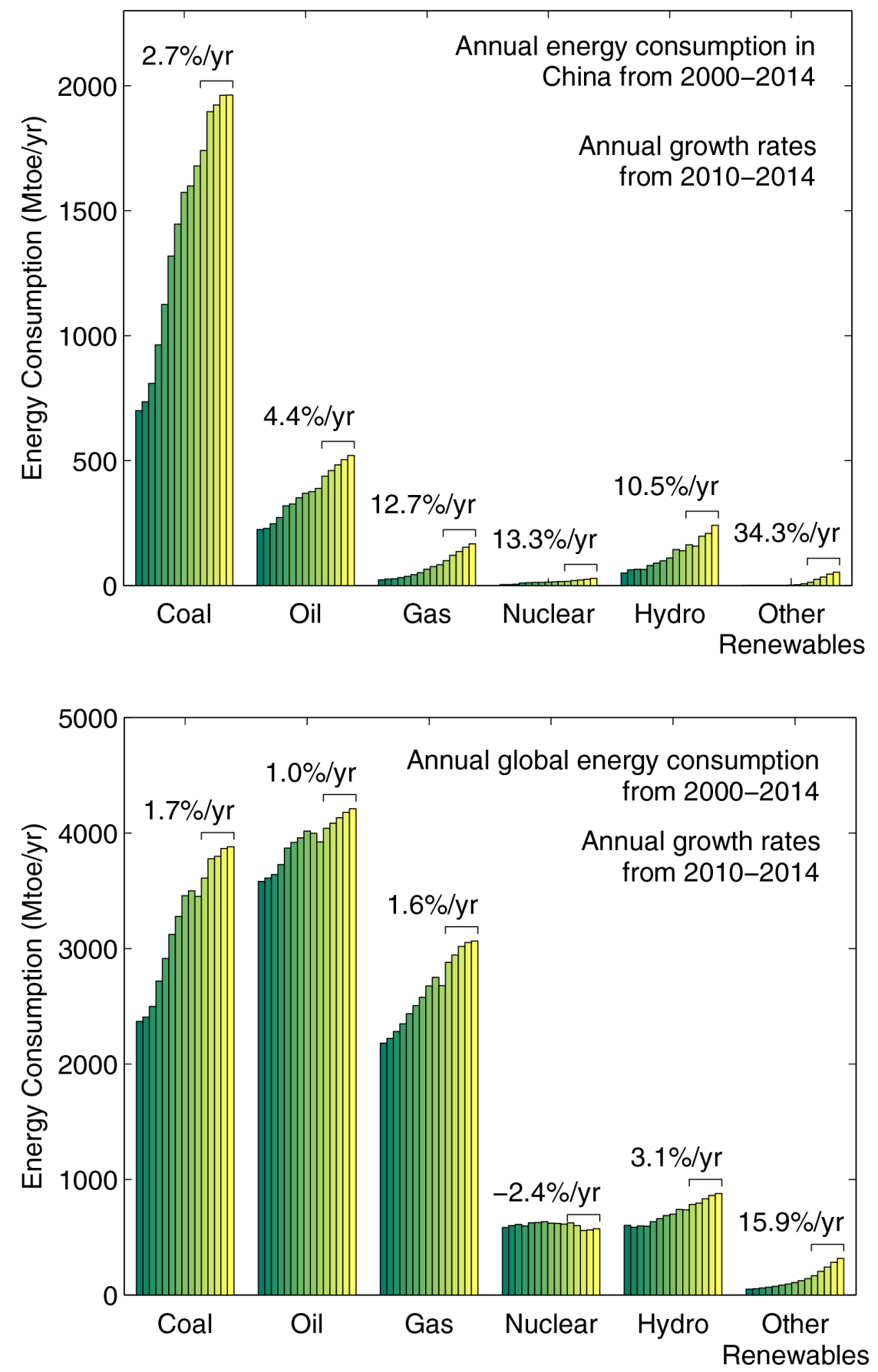

Figure 3. Energy consumption by fuel source from 2000 through 2014, with growth rates indicated for the more recent period of 2010 through 2014. Data presented for a. China, and b. the globe. (Source: Ref 5). 